\title{
Beyond Planning: The Implementation of a Worksite Health Promotional Scheme
}

I Thor Christian Bjørnstad

PhD student at the Norwegian School of Sport Science, Department of Cultural and Social Studies

\section{Kari Steen-Johnsen}

Senior Research Fellow at The Institute for Social Research (ISF), Norway

\begin{abstract}
The aim of this article is to provide insight into how the presence of diverging organizational logics influences the outcome of worksite health promotion projects. The study is based on a one-year qualitative single-case study of the implementation of a health promotional physical exercise program in a transnational transport and logistics company based in Norway. While the program that was implemented was based on dominant logics in Nonway, i.e., the emphasis on worker participation and influence, the organizational logics of the transport company defined company-worker relationships in other terms. We found that the logic of a highly specialized work organization that combined strict work distribution with a set of narrowly' defined work tasks contradicted the logic that underpinned the health promotional program, and that this contradiction is an important reason why the initiative failed. We therefore conclude that in implementing health promotion projects at the workplace, there is a need to observe the relationship between logics related both to the project and to the organization.
\end{abstract}

\section{KEY WORDS}

Institutional logic / health promotion / human resource management / neo-Taylorism

\section{Introduction}

$\mathrm{n}$ recent years, the potential for using worksite fitness and exercise programs to promote public health has received increasing attention in Norway (Handlingsplan for fysisk aktivitet 2005-2009; Ommundsen and Aadland, 2009). Internationally, worksite fitness initiatives are associated with the wider scope of worksite health promotion (WHP), which ranges from single-component measures to comprehensive intervention programs: introducing training modules on smoking cessation, stress management, monitoring blood pressure, cholesterol screening, and nutrition classes, among other things (Weiner, 2009).

This article addresses whether or not existing organizational logics are decisive for the success of implementing worksite exercise as a health-enhancing measure in a specific work organization and if so, how. Based on institutional theory, this begins with

\footnotetext{
${ }^{1}$ Thor Christian Bjørnstad, Norwegian School of Sport Science, P.O BOX 4014 Ullevold Stadion, Sognsv. 220 Norway 0806 Oslo. Email t.c.bjornstad@nih.no
} 
the assumption that organizational logics are basic to how an organization adapts to change. Attention is thus focused on the potential match or mismatch between established organizational logics and the logic of a given health promotional initiative.

Organizational logics may be defined as interpretative schemes, including specific systems of coordination, control, and decision making that determine the issues and problems found to be salient by organizational actors (Thornton and Ocasio, 2008). The case presented in this article, which describes an attempt to introduce a WHP initiative within a multinational transport and logistics company (TransGlobal), provides an opportunity to examine the relationship between two different workplace logics. On the one hand, the logics presented by a health promotion program that was run by the Norwegian Federation for Company Sports (NFCS), and which was firmly embedded in long-standing values and cognitive frames of Norwegian work life, and on the other hand the workplace logics of a multinational company.

The literature on institutional change shows an increasing awareness that logics need to be translated and reinterpreted in order to be integrated into new contexts (Czarniawska and Sevòn, 1996; Rørvik, 2007; Sahlin and Wedlin, 2008). Some authors also emphasize the possibility of having pluralist and contradictory logics within the same organization and hypothesize that such pluralism may lead to ambiguities or to decoupling (Kraatz and Block, 2008). This article contributes to the literature by discussing the consequences of competing logics at the micro level of organizations. It also seeks to expand knowledge about the importance of the local organizational context in implementing initiatives targeted toward employees.

Following a presentation of the theoretical and methodological considerations used, the health promotional scheme that was adapted and implemented in our case is presented. The workplace logic upon which this scheme was based is then emphasized, focusing on how such logics hold certain inherent assumptions concerning the embeddedness within the host organization and the involvement of employees. A brief presentation of the one year project period during which the scheme was adapted is then provided. Thereafter follows a presentation of the workplace logics at the worksite in which the health promotional scheme was implemented. A discussion of how the outcome of this initiative can be explained in light of a confrontation between different workplace logics follows. Based on our findings, a final, more general discussion of how different types of worksite logics may serve to enhance or to hinder the implementation of WHP programs concludes the article.

\section{Contextual preconditions for worksite health promotion}

To our knowledge, no WHP project has been studied within the perspective of organizational logics. So far, the bulk of research literature on WHP has focused on the identification and description of step by-step procedures for program development, deployment, and evaluation (Weiner, 2009). The mainstream of these publications aims to provide best practice recipes for program planning, content, and design (Baun and Pronk, 2006; Kruse, 2009; Pronk, 2010). It is argued that the effectiveness of health promotion programs largely depends on the quality of the project planning (Heward et al., 2007).

Central to WHP literature is the identification of success criteria for the implementation of WHP programs. The development of a worksite health culture is seen as 
a crucial step in order to secure sustainable health-promoting measures. Commitment from top leadership and management is therefore pointed out as an important asset in order to build social support and commitment (Linnan et al., 2007; Plotnikoff et al., 2011; Renaud et al., 2008; Shain and Kramer, 2004; Sparling, 2010). Further, it is recommended that health promotional measures are integrated into related programs and strategies such as worker's safety programs and worksite health services. Combined policies targeting employee health are seen to have a cumulative effect on the worksite health culture, making healthy lifestyles the norm (Sparling, 2010). It is also recommended that programs should be designed to reach all job categories and locations. As all employees have some health risks and needs, programs should have a wide appeal and encompass a range of aptitudes, life stages, genders, education, and cultures. Related to the principle of wide appeal, it is crucial that programs are set up in a way that maximizes their availability. It is therefore seen as important to ensure such things as healthy food options and worksite facilities like showers and locker rooms (Plotnikoff et al., 2011; Shain and Kramer, 2004; Sparling, 2010).

Studies that do address organizational issues related to program adaption and implementation seldom make an issue of the context into which the integration of a health promotional measure is intended. Few studies look at how local organizational circumstances influence the implementation and development of such measures (Emmons et al., 2012; Weiner, 2009). Some of the earlier studies that examined the role of organization primarily considered structural features such as organization size, complexity, and formalization (Drazin and Schoonhoven, 1996; Emmons and Biener, 1993; Emmons et al., 2000; Emont and Cummings, 1989; Sloan and Grumen, 1988; Witte, 1993). Later studies incorporated other features such as organizational readiness (Cherniack, 2010; Faghri, 2010; Rütten et al., 2009; Weiner, 2009;), leadership and management relations (Dellve et al., 2007; Helfrich et al., 2007; Linnan et al., 2007), and organizational culture (Barnsley et al., 1998). It may still be argued that most of these studies address the issue of organizational contexts at a conceptual level (Emmons et al., 2012). By focusing on organizational logics and how they are put into practice at the micro level of implementation, the present study offered a more in-depth perspective of the consequences of organization.

\section{Theory}

In this article, our focus is on how the interface between workplace logics influences the planning and adaption of a worksite physical exercise program. The concept of organizational logics is based on Thornton and Ocasio (2008), who define an institutional logic as "a socially constructed, historical pattern of material practices, assumptions, values, beliefs and rules by which people produce and reproduce their material subsistence, organize time and space, and provide meaning to their social reality," providing organizational members with vocabularies of motive and a sense of self-(identity) (Thornton and Ocasio, 2008: 101). Thornton and Ocasio's definition is derived from Friedland and Alford's (1991) conceptualization of institutional logics. According to Friedland and Alford, society may be conceptualized as a system of various institutionalized sectors. Any given complex of activity within different sectors, such as markets, religion, family, professions, and the state, is governed by specific historically institutionalized logics. 
Within society, its sectors, and organizations, these logics tend to overlap and compete for dominance (Gestel and Hillebrand, 2011; Lounsbury, 2008). The way actors, such as certain professionals within given fields, try to promote certain logics creates competition, conflict, and innovation, which in turn creates a certain level of heterogeneity among the ways people tend to organize their activity (Scott, 2008).

According to Friedland and Alford (1991: 253), "Society is composed of multiple institutional logics which are available to individuals and organizations as bases for action." Organizations are confronted with various institutional logics that are then translated and enacted as local organizational logics. Such logics work as interpretative schemes and include specific systems of coordination, control, and decision making, determining the issues and problems that are found salient (Spicer, 2006; Thornton and Ocasio, 2008). The adaption of the WHP program is analyzed in terms of a sense-making process. Our focus is on how organizational logics equip people with the assumptions, values, beliefs, and rules that form their frames of interpretation and ability to constitute local and concrete versions of more general ideas of WHP (see, for example, Rørvik, 2007). Organizational logics are thereby understood as the sense-making frames that provide understandings of what is legitimate, reasonable (natural), and effective in a given context (Spicer, 2006). As such, they provide broad limitations to the possible actions that people can undertake. Frames in this context are understood as a product of past moments of socialization, which, in confrontation with present moments of experience, constitute meaning (Weick, 1995: 111). The adaption of a health promotional scheme is thereby a (social) construction that is made up of the relationship between (past) organizational logics in terms of assumptions, values, beliefs, and rules and the (present) encounter with new experience and ideas. The new experience in our case involves the introduction of health promotion by the means of a worksite physical exercise program. This program is inherently based on its own underlying logics, which in turn guide the organization and adaption of the program. Accompanying logics will naturally depend on the sources from which providers of such programs derive their knowledge, as well as on how they accumulated experience from different parts of work life. In the end, such knowledge and experience will shape the assumptions, values, and beliefs on which actors in the field of WHP base their programs. As a consequence, the outcome of adaption will depend upon the level of compatibility between the underlying organizational logics associated with the introduction of the respective health promotional program and those logics that underpin the host organization.

\section{Case}

The research presented in this article is based on a qualitative case study of the adaption and implementation of a physical exercise program aimed at employees that did not exercise regularly. The program was provided by the NFCS, a voluntary organization with a long tradition of organizing company sports in Norway. A local project group was appointed to carry out the program. The workplace in which we studied the program is a typical case of an organization that is highly specialized around a narrow set of well-defined work procedures. The workplace is the Norwegian terminal of a global logistics and transport company, TransGlobal. The terminal has been located in Norway for approximately twenty years. It is organized around the transnational distribution of 
parcels and commodities and is part of a globally integrated system. Parcels arrive at the terminal by truck, are manually unloaded, scanned, and sorted, registered for the customs service, and then loaded back onto trucks and further distributed. The Norwegian terminal belongs to the North European center of coordination situated in Stockholm, which reports to the European headquarters located in Brussels. Given the fact that decisive authority is located at the European level, the system implies a relatively high degree of centralization and considerable distance between lower and higher levels of managerial positions. To compensate for this, distance work processes are characterized by extensive control and incentive systems.

\section{Method}

Our research is based on a one-year qualitative case study, involving on-site observation of the project work in progress, interviews, and reading of company documents, including standardized procedures and educational pamphlets. The study was designed to capture the process of planning at the micro level, while at the same time identifying operating organizational logics. The first author followed the work of the project group during the one-year-long project period, attending all project meetings, and was granted access to the e-mail correspondence between project participants. Access to e-mail correspondence provided an opportunity to follow the project work in between group meetings. The project group consisted of the worksite Human Relations Manager (HR manager), four internally recruited coworkers, and one external project consultant representing the NFCS. The project consultant was to assist in organizing the project. The coworkers recruited held non-managerial work positions and came from different departments within the company. By observing the project group, we were able to record the group's interactional patterns. Our focus of attention was on the topics and problems that the group prioritized. It was important to establish the circumstances under which these topics were introduced and by whom. In this respect, we were interested in the work distribution that settled within the group in terms of the roles and functions that were collectively ascribed to the individual participants.

It was important to gain insight into the individual group members' reflections about their participation in the project and how these reflections changed during the course of events. Each group member was therefore interviewed on two occasions, first at the beginning of the project and then toward the end of the project period. A group interview with the project group was also carried out after the project was terminated. In addition, the first author had several conversations with the group participants. The combination of observation and interviews gave us the opportunity to interpret the project process in light of the group members' reflections and self-conceptions. The interviews lasted between forty and ninety minutes and focused on topics such as the project participant's interpretation of project work and their experience as participators in the arranged exercise activities. Topics also included the operation and organization of the workplace. The interviews with the project consultant also provided information about NFCS as a WHP provider and the intentions and thoughts underpinning their program. This interview material was supplemented by the NFCS project descriptions, the NFCS web site, and general literature on the NFCS as a voluntary organization. Taken to- 
gether, this material provided a detailed insight into both the planning process and how it was interpreted by the involved project members.

To gain a comprehensive understanding of how work was organized at TransGlobal, eight of twelve team leaders were interviewed. Each team leader worked at shop floor level together with the coworkers that they supervised. Team leaders were also interviewed about their experience of the physical exercise program. These data were supplemented by documents that described standardized procedures and by educational pamphlets directed at managers.

The authors believe that this approach enabled a more dynamic perspective than is usually the case within the WHP literature. Few studies on the implementation of health-enhancing measures follow the development of such processes over time (Bull et al., 2003). Our longitudinal approach that combines observations with interviews and written material made it possible to deal with complex sets of events and processes and to observe how they unfold over time (Miles and Huberman, 1994).

\section{Analyses}

Transcribed interview material, observation notes, and document texts made up the basis for analysis. Our objective was to provide insight into how the presence of diverging organizational logics influenced the outcome of the exercise project.

The project process was analyzed on the basis of observed interaction patterns within the project group, i.e., how these patterns focused group members' attention on certain dominant interpretations and meaning constructions. Moreover, an attempt was made to see how authoritative interpretations and intent mediated by interactional patterns were influenced by prevailing organizational logics. To do this, a construct of the logics inherent in both the NFCS program and the host organization was generated. The organizational logics of the NFCS program are based on the corresponding values, assumptions, and rules that emerged from three different sources: the interviews with the NFCS consultant, the NFCS program description, and existing literature on the NFCS as a voluntary nonprofit organization. Subsequently, the organizational logic of the NFCS program was interpreted as a continuation of the Norwegian work-life model, as described inter alia by Kalleberg et al. (2009) and Engelstad et al. (2003).

Similarly, a construct of the organizational logics of TransGlobal was generated based on the prescribed values, expectations, and rules present in policy documents, educational pamphlets, and standardized work procedures. These organizational logics were interpreted as an expression of Taylorism, as presented by, e.g., Rørvik (2007). Material from interviews with the team leaders and the project participants was in turn used to verify that these centrally initiated values, rules, and procedures were enacted in the operation of the local worksite.

Finally, we analyzed the interactional patterns of the project group in light of the organizational logics in order to detect the extent to which the assumptions, values, and rules that guided the project work matched those of the organizational logics. By comparing the organizational logics with the observed interactional patterns, we were able to see the degree to which the interactional patterns represented an enactment of the two diverging logics (TransGlobal versus the NFCS program). 


\section{The logic of health promotion: the case of NFCS}

NFCS has a long tradition of organizing traditional company sport in Norway. The organization has been part of Norwegian work life since the 1930s. Both the Norwegian Confederation of Trade Unions and the Confederation of Norwegian Enterprises (CNE) have traditionally held prominent seats on the board. According to Gulbransen (2009), this illustrates how company sport is seen as an important part of the cooperation between the main interest organizations in Norwegian work life, partly evident in how both organizations have provided funding to NFCS.

The primary aim of NFCS has been to promote health through traditional competitive sports activities. On their web site, NFCS claims to have 4450 company sport teams and 300,000 members. During the last decade, NFCS has developed a new concept aimed at reaching employees that do not comply with the health authority's recommendation of at least thirty minutes activity every day. This concept is based on pilot projects conducted between 2004 and 2006. In 2009, similar projects guided by NFCS involved nearly thirty companies, ranging from private and public sector businesses as well as voluntary organizations.

The particular program provided in our case was part of a joint venture between NFCS and CNE. CNE wanted increased attention placed on preventive measures as part of health promotion activities among member companies. They therefore requested NFCS to assist by providing their program to CNE members. The project was therefore also funded by the CNE working environment fund, which implied that participating companies did not have to provide funding beyond paying a membership fee to the NFCS.

According to the NFCS project description, a key feature of the program is that it should be considered as part of the overall health and safety work at the workplace. As such, the program is in line with the current agreements on the working environment, inclusion, and employment policy in Norwegian work life (Gulbransen, 2009). This agreement, known as the "Inclusive Working Life" scheme, was prepared on behalf of the main special interest organizations. Its main purpose is to reduce absence due to illness, improve the working environment, and prevent long-term exclusion from work life (March 1, 2010, to December 31, 2013).

At an organizational level, the values and expectations of work life are expressed in the NFCS project description. This states that the program is subjected to certain preconditions. These preconditions are poorly elaborated, but hint at what is emphasized as important, both in relation to values and expectations prevalent in work life and in terms of securing a good implementation. The program says that local ownership and implementation are seen as important cornerstones in the program, and it is considered as essential that recruitment to project groups is voluntary. The establishment of local project groups implies that coworkers are included in the decision-making processes concerning adaptions of the local programs. The project description also says that the project should involve the relevant local labor organizations together with the company leadership. This implies a working environment committee, a deliberative arena where representatives from the company leadership can discuss working environmental issues together with employee representatives. In addition, the company health service and the company sports team should be part of the group. Furthermore, the respective companies must anchor the program within their own plans and policies. The program 
should thus be categorized as part of the safety, health, and environmental work within the company.

The health promotional program reflects the particular position of NFCS as an organization that operates across the borders of the voluntary sector and work life. The preconditions listed for program implementation reflect the way central values present in Norwegian work life have been translated into guiding organizational logics. Values like worksite democracy and worker participation have been a central feature in the work ethics of the Nordic countries. As an outcome of class compromises, welfare states, and a work life formed by strong organizations and close partnership cooperation between work-life interest groups, these values have become an institutional part of work life (Kalleberg et al., 2009). The significance of such values is also reflected in recent comparative studies claiming that Scandinavian workers perceive a higher quality of working conditions and interpersonal relations, better opportunities for participation, and more autonomy than do workers in other EU countries and in the United States (Esser and Olsen, 2011; Kalleberg et al., 2010). The prescribed formation of local project groups is a continuation of these expectations and values. The way employees are expected to participate in established deliberative arenas, where employees and employer can come to solutions that reflect both parties' interests, is a strong reference to work-life democracy. Participation of both parties is presented as a means of creating local ownership among both employees and the employer. Democracy is thus seen as a precondition for good implementation. In this respect, cooperation is a key value and necessarily present in terms of securing integration of the program within the work organization, and more specifically within safety, health, and environmental policies. The focus on safety, health, and environmental policies is a continuation of the past two decades of increased attention to such issues at the national level. Safety, health, and environmental policies have been an important theme in the work of the national work-life interest organizations.

In addition, the NFCS program is also a bearer of values and assumptions that are traditionally associated with the voluntary sector. The program is based on voluntary participation from the companies as well as the employees. Company representatives are expected to contribute through facilitating time-use and resources in terms of project work and preparation of action plans and concrete program measures. The employees are for their part expected to prioritize and find time in their work schedules to set aside time in order to participate in project groups and help in the arrangement of activities and events in their leisure time. The NFCS program is therefore built upon the premises that to a certain extent blur the borders between work and private life.

\section{The logics of TransGlobal production}

As a multinational company, TransGlobal emphasizes its American heritage and seeks to standardize its global organization as far as permitted by national laws.

HR manager: (...) everything that has to do with Norwegian law is my responsibility, to follow up and make sure that we actually follow Norwegian law. So it is a lot to keep track of, both according to TransGlobal and Norway, it is about finding a balance, and that is hard, (...) but we are very American in a way. 
TransGlobal follows an Anglo-American work-life model with respect to companyemployee relations. The Scandinavian work-life model, contrary to the Anglo-American model that is dominant at a global level, is primarily based on ownership as the formal basis for co-participation and influence (Engelstad et al., 2003). This model is also more market oriented (Dyreborg, 2011), creating a weaker foundation for workers' rights than the Scandinavian model.

The organizational logics applied in the TransGlobal terminal are equivalent to what is often described as scientific management, Taylorism, or neo-Taylorism (Watson, 2009). As an institutional logic for organizing mass production, Taylorism constitutes a broader belief system that shapes the cognition and behavior of actors. Taylorism is often presented as a phenomenon of the past, having had its day during the 1940s and 1950s. This is far from the case considering contemporary organization of mass production. Newer approaches to manufacturing processes such as lean production represent a continuation of such principles (Skorstad, 1999). Tayloristic principles have also traversed beyond the field of industrial manufacturing and are widely applied in service work, known for example as the McDonaldization of the fast food business (Watson, 2009).

Taylorism is based on the principles that behavior and organizational resources are channeled toward organizational goals by means of centralized leadership, directives, formal structures, and standardization through technology, procedure, and routine (Rørvik, 2007). This use of special-purposed, instrumental technologies and procedures invokes institutional processes that constitute and define the capacities of (collective) actors (Scott, 2008). The institutionalized controlling power of the system is due largely to the fact that the nonhuman artifacts (such as machines and automatic control devices) strongly affect the work practices. As a consequence, employees' expectations in terms of motivation and a sense of self are in part made up of machine technology and are thereby somewhat removed from the everyday awareness of the workers (Joerges and Czarniawska, 1998).

In our case, the worksite is an integral part of a large transnational structure, with great spatial distance between lower levels of management and the deciding authority. The orchestration of the worksite is based on the central principle/logic of making the distribution of goods as efficient as possible. Efficiency thus means minimizing the time and resources that are used per dispatch by unremittingly limiting production to that which is strictly necessary. This central principle is supported by a list of other logically following measurements concerning the organization of the worksite.

The organization operates through a set of strictly defined work tasks that are controlled by corresponding hierarchical lines of authority. The HR manager puts this explicitly in her description of how she conceived the employees' expectations of the company: "They know what they are up against, as everything is already defined; what you are supposed to do and what not to do and so on." Thus, planning activity is separated from its execution and workers at the shop floor level do not take part in planning processes.

The design of work positions in this system is highly integrated and specialized according to the flow of dispatches through the terminal. This involves a relatively high degree of compartmentalization where each workstation carries out relatively standardized, well-defined, repetitive, and narrow work tasks. Thus, employees carry out the same tasks each day. There is a minimum of interaction between the various work 
stations and employees have relatively little control over work procedures in terms of how the work is carried out, planning, and time distribution. Skill requirements are overall low and relatively little time is spent on job learning on an individual basis.

Because the terminal is part of a globally integrated process, it is vulnerable to divergence at a local level. This is why the company tries to achieve predictability through global standardization. In order to achieve predictability, the work process is subjected to a tight managerial regime. This is exercised through a direct control strategy including close supervision. At the team level, operations follow standard worksheets specifying the order of operations and the time allowed for them. Teams are supervised by a team leader, performing production as well as supervision. As far as discretionary power is delegated to the team level, this is exclusively related to monitoring the work flow, as standardization is relentlessly pursued at this level.

This monitoring is supported by a technical control strategy, implying extensive use of time studies as the daily work is registered and reported both automatically and manually. The HR function in this system is concentrated on administrative tasks such as recruitment, salary and compensation, personnel, organization of internal learning, health, and safety. Direct and technical control strategies are combined with a bureaucratic strategy. Central to the bureaucratic strategy is the construction of an internal career structure (Watson, 2009). An important function of the career structure is to encourage reasonable and predictable levels of performance. In this respect, TransGlobal prioritizes internal recruitment of managers. By recruiting relatively young managers with limited experience from general work life, the company strengthens their ability to exercise cultural management.

Employee: The mangers are very young, and some of them are characterized by being here their entire career. (...) This implies that they are, uh, very square, and focused on exactly that part of the job that TransGlobal has as their policy.

Management recruits are put through successive internal training programs, which they have to pass in order to advance further up the career hierarchy. TransGlobal takes the implications of its own rhetoric seriously and invests considerable energy in trying to incorporate its rules, prescriptions, and admonitions into the everyday life of the workplace. Regulative, normative, and cultural cognitive elements are infused into the organization (Selznick, 1984: 17) with the aid of the company's internal training system. In their educational material and codes of business conduct, the company emphasizes its continual attention to the values of its founding fathers.

Can a modern industry leader bear resemblance to a small startup in 1907 (...)? It can. But only if during each growth stage it passes on a legacy of excellence - in leadership, purpose, and service. In short it must value its culture.

References to this legacy were apparent in the HR manager and team leader's description of the company's identity:

HR manager: We have a lot of guidelines and policies, and a policy book that we have to follow; and some of these are actually over a hundred years old. 
This educational system plays an important role in the aforementioned adaption of an Anglo-American work model to a Norwegian context and creates a certain protection against external normative institutional pressure. It helps the company to search for cultural unity by promoting (as stated in one of their policies) “... the same understanding of philosophies, guidelines, and uniform practices that shape our actions.” The company's effort for cultural uniformity was reflected during the first interview with the HR manager, as she explained that "this is not Norwegian work life."

\section{The process of implementation}

The national manager of TransGlobal Norway was responsible for taking the initiative to participate in the program. She became aware of the program after attending a meeting in the company's national business association where the program was introduced. The country manager then appointed the local HR manager to implement the program. At the beginning of April, the HR manager published the intention and content of the program on the worksite intranet and called for volunteers to join the project group. In May, the HR manager and the NFCS project consultant came together for a meeting. The intention was to enable the NFCS guide to provide an in-depth briefing about the program to the HR manager and to define the immediate preparatory measures to get the program up and running. This included several practical arrangements that were agreed upon by the HR manager and the consultant. In the ensuing days of May, the HR manager and the project guide began to work on these tasks. At the end of June, the entire project group assembled for the first time. Besides the NFCS consultant and the HR manager, the group consisted of one terminal clerk, an employee from internal marketing, a salesperson, and an employee from the customs department.

According to the NFCS project description, the project group was supposed to do an overall mapping of the worksites' prior health and safety measures as well as of the needs and preferences for physical activity among its employees. A physical walking test was also to be conducted to provide a baseline for measuring eventual improvement of employees' physical capacity. Based on the initial mapping, the group was to customize a program consisting of low threshold activities, possible nutrition courses, social activities, competitions, and campaigns. All these were to be presented on an internal webpage provided by NFCS. This webpage was a central tool for launching campaigns and to motivate employees to increase their physical activity through competitions. To carry out the project, the group was supposed to develop an action plan that contained concrete measures and activities based on the initial mapping. At the end of the project period, the program was supposed to be evaluated. Observations of the planning process were systematized by categorizing observation material with respect to the three categories of measures used by the project group. These are preparatory measures aimed at getting the program up and running; promotional measures aimed at generating immediate activity, motivation, and attention; and organizational measures aimed at anchoring a sustainable program within the work organization (Table 1).

During the five meetings that the group managed to arrange, most of the time was spent on planning preparatory measures. Campaigns were among the main promotional measures, representing a key element in the program. The first campaign was launched in the aftermath of a kickoff. Even though the first campaign was perceived as 
Table I Program history.

\begin{tabular}{|c|c|c|c|c|c|}
\hline & $\begin{array}{l}\text { Ist meeting - } \\
\text { June }\end{array}$ & $\begin{array}{l}\text { 2nd meeting - } \\
\text { August }\end{array}$ & $\begin{array}{l}\text { 3rd meeting - } \\
\text { January }\end{array}$ & $\begin{array}{l}\text { 4th meeting - } \\
\text { May }\end{array}$ & $\begin{array}{l}\text { 5th meeting - } \\
\text { June }\end{array}$ \\
\hline $\begin{array}{l}\text { Preparatory } \\
\text { measures }\end{array}$ & $\begin{array}{l}\text { Web site } \\
\text { E-mail } \\
\text { addresses } \\
\text { Campaigns } \\
\text { Kickoff } \\
\text { Internal } \\
\text { marketing } \\
\text { Activity groups }\end{array}$ & $\begin{array}{l}\text { Kickoff } \\
\text { Internal } \\
\text { marketing } \\
\text { Campaign } \\
\text { programming }\end{array}$ & $\begin{array}{l}\text { Counter } \\
\text { decrease in } \\
\text { interest in } \\
\text { campaign } \\
\text { Planning more } \\
\text { activities } \\
\text { Kick off } \\
\text { Soccer cup }\end{array}$ & $\begin{array}{l}\text { Use of } \\
\text { project } \\
\text { budget } \\
\text { Planning } \\
\text { activities } \\
\text { Campaign } \\
\text { programming }\end{array}$ & $\begin{array}{l}\text { Use of } \\
\text { project } \\
\text { money } \\
\text { Planning } \\
\text { activities } \\
\text { Campaign } \\
\text { programming }\end{array}$ \\
\hline $\begin{array}{l}\text { Promotional } \\
\text { measures }\end{array}$ & & $\begin{array}{l}\text { Kickoff } \\
\text { Buying prices } \\
\text { Walking test } \\
\text { Information } \\
\text { sessions } \\
\text { Feedback from } \\
\text { physical test } \\
\text { Launched } \\
\text { campaign }\end{array}$ & $\begin{array}{l}\text { Soccer cup } \\
\text { Launched } \\
\text { campaign }\end{array}$ & $\begin{array}{l}\text { Recruiting } \\
\text { people for } \\
\text { activity }\end{array}$ & \\
\hline $\begin{array}{l}\text { Organizational } \\
\text { measures }\end{array}$ & & Soccer group & & $\begin{array}{l}\text { Badminton } \\
\text { group } \\
\text { Buying sport } \\
\text { equipment }\end{array}$ & \\
\hline
\end{tabular}

quite successful, participation dropped steeply, from 82 employees in the first campaign to just 23 in the second. The third and last campaign had 34 participants.

As for the organizational measures, the group did manage to organize a soccer group. They also planned to organize other activities, but these plans never led to concrete measures. Even though the initial survey was a tool to identify needs and target groups among the employees, it was never used to define organizational measures that could be used in the implementation process. First and foremost, it was used to identify popular activities to arrange. The activities listed were all traditional sports activities and not low-threshold measures targeting people with little exercise experience. Soccer, for instance, scored high $(42 \%)$, and the group quickly agreed to organize this activity.

The group was unable to spend the funds budgeted for the project, which clearly illustrates how they struggled to organize project activity. The intended action plan was never discussed and no clear goal or intentions were ever identified. Group discussions generally focused on promotional measures, such as changing the campaign rules and introducing new prices. The group decided to buy some sports equipment for the soccer team and to set up a badminton group in addition to launching a new campaign. However, the newly started badminton group was canceled due to poor attendance. By the time the one-year project period had expired, the soccer group that had been established also dispersed. Although this was not the intention, the fifth meeting turned out to be the last. The group was not able to get together again, which also quashed the intended project assessment. 
Most of the time and attention during project period had been spent on preparatory and promotional measures. Even though it was seen as important to create a sustainable program through organizational anchorage, group participants had no idea of how to work toward such organizational objectives. The closest they got was to organize classical competitive company sport, which hardly corresponded to the initial intention of the project. Even though the project failed, the company reserved a plaque from the NFCS, confirming that they had been part of the project. This failed process was, as we shall see, due to the mismatch between the workplace logic of TransGlobal and the logics inherent in the NFCS health initiative.

\section{Logics of organization and patterns of interaction}

The process of adapting the exercise program came to a halt before realizing its intentions and goals. Questions of how to align project work in accordance with the initial program intentions were overshadowed by the urgency of defining preparatory and promotional measures. The focus was partly on campaign work and facilitation of opportunities for exercise. The group did not work on how the targeted group of employees could be reached or on how to facilitate exercise groups that actually corresponded to the needs of low-activity employees. An investigation follows of how the lack of knowledge, partial focus, and poor project facilitation and a consequential loss of affiliation could be read as being a consequence of incompatible organizational logics.

The development and local adaption of the NFCS program is based on the values of work-life democracy and the existence of deliberative arenas where employees and employer representatives come to solutions through cooperation. In TransGlobal, no such arena exists. Neither the HR managers nor the recruited employees had prior experience with cooperation over matters of health and working environment. This became crucial for the adaption of the program. The NFCS project consultant had no strategies targeting organizational measures. This is something that the consultant, pursuant to the NFCS project description, assumed that the company would take care of. Organizational matters in terms of project management, program adaption, and implementation are not within the NFCS portfolio. The quality of the program is thereby very much dependent on the interests and preferences of the respective companies and their employee representatives.

Interviewer: $\quad(\ldots)$ so you are dependent on the company?

NFCS consultant: Very dependent (...). We have been much occupied with the sales bit, and campaigns and activities; we have been very focused on that, and not so much the HR bit and the anchoring of the project (...).

Interviewer: And it is my impression that, when you arrived at TransGlobal, they did not know what they wanted to do with the project?

NFCS consultant: I agree that is a good point.

The project group suffered from a lack of ability to articulate an interest in the program. They were not able to set up goals and strategies beyond preparing and carrying out the promotional measures introduced by the project consultant. 
As institutions provide meaning to their social reality, providing organizational members with vocabularies of motive and a sense of self, they also distribute the interests of their members. Based on the Norwegian work-life model, the NFCS program took the interests of employees for granted. According to the project description, it was intended that employees would participate in the project group. This was supposed to promote a feeling of ownership among employees. But TransGlobal does not facilitate deliberative arenas to promote workplace democracy. The company does not include terminal employees in projects. The rule is a clear separation between planning activities and the execution of work. Planning is assigned to departments separated from the terminals. Therefore, recruited project members had no prior experience to guide their interest in terms of what to do and how to do it. The goals of the project and the roles of the group members were never the subject of debate. Consequently, the terms on which they were invited to participate were not clear.

Project member: It does not bear the impress of a go-ahead spirit exactly. But that is because it is something new and, it is a bit odd, because, I am not sure if we have managed to grasp what this is, in a way. I do not think that any of us who participated knew what it was in a way.

The project group suffered from a lack of ability to articulate an interest in the program. They were not able to set up goals and strategies beyond preparing and carrying out the promotional measures introduced by the project consultant. Not really knowing what to expect concerning the aim of the project and their roles as group members was draining on the participants' motivation. It consequently became hard to maintain a focus on the project.

Project member: It is a bit of course, and now it is even more like, we do not talk to each other before meetings and, well for me that is all right, I do not know how much we gain from it. As for my part, is it really necessary that I am present?

Because the HR function in this system is directed toward administrative tasks, the HR manager, who was appointed to carry out the program, also lacked experience with similar projects.

Interviewer: Did you have any strategy on how to carry this out, the project, how to run a project group, that kind of thing?

HR manager: I do not think we had any strategy in advance, but I suppose it sort of came a little bit as we moved along. What I knew was that the NFCS consultant was going to be part of this; he was our adviser in a way. I have never done something like this, so it was a bit hard to come up with a strategy.

According to Thornton (2002: 83), ambiguity and cognitive limitations make it difficult for individuals to attend to all aspects of their organizational realm. Thus, organizational logics help to focus attention toward a limited set of issues. As Weick (1995) points out, within these familiar limitations employees feel safe and therefore seem to 
reproduce them. In TransGlobal, familiar limitations are present in terms of a strict work distribution combined with a set of narrowly defined work tasks. Employees usually work within specified areas of responsibility, conducting the same kind of procedure every day. Under exceptional situations, they would be told what to do. These were expectations that were evidently conveyed to the project group, as the recruited members tended to sit and wait for instructions during the project meetings. They generally said little and would not contribute to the conversation beyond the frames presented by the HR manager or the NFCS consultant. The consultant's inability to contribute to the organizational integration of the program within the worksite brought frustration to the group. They wanted someone to lead them through the process.

Project member: It would be easier if he was hard and brutal, and told us, (...) it would be easier to relate to, instead of discussing something that we really did not know, uh, what (laughter) was. If I sit there in a meeting and say something, I do not know if it is any good, if we can gain anything from it.

As shown, this was not the case. Considering organizational measures, the project consultant did not know how to proceed. The result was a collective aloofness and demonstrates the project members' dependence on the consultant and the HR manger. This exemplifies the meaning of past moments of socialization. Leaving the functional structure, where normal procedures of conduct are no longer valid, does not automatically imply that one's roles and self-perceptions are free from organizational bureaucratic control (Kunda, 1992: 220). So, even though the project members left their ordinary work stations and moved over to the local meeting room in order to work on the project, they remained within the cognitive limitations of their work positions.

The lack of prior experience and confusion over how to proceed with the project is a consequence of the unremitting focus on limiting production to what is strictly necessary. The consequence of this regime was apparent, for example, in terms of eventual exercise during work hours.

HR manager: Activity during work time? Well a work position is built around the principle that you shall do so and so, and then we say rather one work task to much, than one too little. You are supposed to get a lot of work done during a day. You are supposed to fill up a workday.

According to Pruijt (2003: 85), the HR manager's description of a proper workday is central to a Tayloristic system. The ideal is that the actions of workers should consist entirely of work that adds value to the product. Activity beyond that is perceived as waste.

HR manager: Especially the women, they want social events, primarily during work hours, and that is not possible in TransGlobal, we already have enough to do (...). TransGlobal does not accept that principle. TransGlobal only gives compensation when it is a reward, which is when a reward is earned. (...) The job that we expect them to do, that is what we are already paying for, if you know what I mean. 
In light of such a strict regime of priorities, the project appeared as extraordinary.

Interviewer: What is your impression of how the company welcomed this exercise project?

Employee: $\quad$..., strangely positive in a way. Because this company is restrictive on everything new, also in relation to social arrangements and such, they are very reluctant, reluctant to everything outside those square walls that is work.

As an extraordinary exception to the rule, the program appeared to suffer from low legitimacy in terms of being perceived as less desirable and appropriate. Expectations of its low legitimacy were expressed, for example, by the way the HR manager felt reluctant to introduce the program to other senior managers.

HR manager: (...) but first I would have to convince my superior, who is German and maybe not so, not so inspired by such projects. It's much more like bang, bang, bang, work and a little bit other expectations.

As a consequence of the project's low priority and legitimacy, the project group was left in solitude. The group never received any indication or clues of what the company expected of the program in terms of outcomes, ambitions, or responsibilities. In light of the company's pursuit of extensive standardization and the need to avoid local deviation, it follows that the group would have needed support from senior managers to be entitled to introduce organizational measures that involved changes at a local level. Consequently, they could not include the program as part of the safety health and environmental policies nor integrate the program as part of the organization in any other way. Even though stated as important in the NFCS project description, these issues were never enacted by the project group.

So far, our investigation reveals that the program failed due to the logical incompatibility between the organizational principles of the WHP program and those of the worksite. A crucial precondition for the success of the NFCS program is the existence of deliberative arenas. The NFCS project was a continuation of the Scandinavian work-life regime, which values high-quality working conditions in terms of interpersonal relations and more opportunity for participation. This is a necessary precondition for developing deliberative arenas at the worksite. In TransGlobal, on the other hand, the relationship between worker and employee is primarily defined according to ownership and the logic of unremittingly limiting production to what is strictly necessary. TransGlobal distributes leadership and decisive authority by means of an extensive use of bureaucracy. The further one moves from the vertex toward the base in this model, the more limited the control over company knowledge and resources becomes (Burns and Stalker, 1994; Mintzberg, 1979: 72; Perrow, 1986). The expectations of workers in terms of their position, value, and legitimacy are thereby an expression of how the company-employee relationship is reduced to an economic exchange, leaving out topics not directly related to core functions. Thus, the company had no democratic arena in which employee representatives were socialized into a culture that allows for their co-participation in developing a better work environment. Such a culture has to be maintained if worker representatives are to achieve the knowledge and proper self-perception necessary to 
develop the interest to contribute to programs such as WHP. When this interest is absent, the participants involved lack the ability to develop clearly defined intentions and goals within the current structure of possibilities.

\section{Conclusion}

The aim of this article has been to provide insight into how the presence of diverging organizational logics influences the outcome of WHP projects. While the program that was implemented was based on dominant logics in Norway, such as the emphasis on worker participation and influence, the organizational logics of the transport company defined company-worker relationships in other terms. The attempted adaption of the NFCS program came to a halt because the underlying organizational logics of the program were not compatible with the underlying organizational logics of Taylorism. The NFCS project description states that the program should follow certain preconditions. It says that local ownership and implementation are seen as important cornerstones in the program. The program should therefore involve employees who are voluntarily participating, relevant labor organizations together with the company leadership, the working environment committee, the company health service, and the company sports team. The program's premises thus assume that any prospective host organization will have inherently internalized the core values and expectations of Norwegian work-life democracy.

In contrast to the Norwegian model, the expectations and core values of TransGlobal have their origin in the Anglo-American model. In this model, the formal basis for co-participation and influence is ownership (Engelstad et al., 2003). The model has no room for the presence of deliberative arenas in work life and sees these as less valuable. In accordance with these expectations, the company has no democratic arena in which employee representatives are socialized into a culture that allows for their co-participation in developing a better work environment. Instead, the self-perception of employees and lower level managers, as illustrated in our case, is structured according to the logic of Taylorism. This implies that expectations of the function and the meaning of work positions are in accordance with the logic of a highly specialized work organization that combines strict work distribution with a set of narrowly defined work tasks. These patterns are sustained through a direct control strategy, including close supervision, combined with a technical control strategy, implying automatic and manual registration of the work flow. Direct and technical control strategies are combined with a bureaucratic strategy. Central to the bureaucratic strategy is the internal career structure, based on promotion from entry-level positions and internal training programs. The combination of strategies plays an important role in the adaption of the Anglo-American work model mentioned within a Norwegian context. These strategies keeps employee influence at an arm's length, as well as securing the company's identity by infusing regulative, normative, and cultural cognitive elements by means of internal training programs (Selznick, 1984). This is how the company, as a global actor, deals with the challenges of pluralistic institutional environments. The company, using a definite strategy of standardization on a global level, protects itself against local institutional environments, preserving its roots in the Anglo-American model.

It seems clear that health promotion based on employee participation, meant to be adopted and implemented at a local level, represents a contradiction to the institutional 
foundation of Tayloristic logic. Thus the outcome of adapting general organizational ideas like WHP has been shown to be determined not only by the institutional guidelines that follow WHP programs but also and often misrecognized in the WHP literature by the institutional logics that guide the operation of the worksite. It will therefore be fruitful to further investigate how successful adaptions are related to the prevailing logics that guide organizational behavior and how such organizational logics are related to their institutional societal environments. In this respect, it would be interesting to further investigate how organizational logics define company-employee relationships and how these might influence the wider distribution of WHP. As shown in this article, this is important in a general sense because neo-Tayloristic bureaucracy tends to dominate in sectors that recruit people with relatively little education. Research has shown that low education correlates with cardiovascular diseases, and that such diseases are associated with work environment problems such as a feeling of little control over work tasks and lack of social support at work (Eldstad, 2008). It is therefore important to understand how the institutionalized premises for work organizations represent a systematic social impediment in the use of work life as a platform for the promotion of health.

\section{References}

Barnsley, J., Lemieux-Charles, L., \& McKinney, M. M. (1998). Integrating learning into integrated delivery systems. Health Care Management Review, 23, 18-28.

Baun, W. B. \& Pronk, N. P. (2006). Worksite health promotion: Good programs don't just happen - they're planned! ACSM's Health \& Fitness Journal, 10, 40-43.

Bull, S. S., Gillette, C., Glasgow, R. E., \& Estabrooks, P. (2003). Work site health promotion research: To what extent can we generalize the results and what is needed to translate research to practice? Health Education \& Behavior, 30, 537-549.

Burns, T. \& Stalker, G. M. (1994). The Management of Innovation. Oxford: Oxford University Press.

Cherniack, M., Morse, T., Henning, R., Seidner, A. \& Punnet, L. (2010) Health Promotion Site Selection Blues: Barriers to Participation and Implementation. Journal of Ocсupational and Environmental Medicine, 52, 626-634.

Czarniawska, B. \& Sevòn, G. (Eds.) (1996). Translating Organizational Change. Berlin: Walter de Gruyter.

Dellve, L., Skagert, K., \& Vilhelmsson, R. (2007). Leadership in workplace health promotion projects: 1- and 2-year effects on long-term work attendance. The European Journal of Public Health, 10, 1-6.

Drazin, R., \& Schoonhoven, C. (1996). Community, population, and organziation effects on innovation: A multilevel perspective. Academy of Management Journal, 39, 1065-1083.

Dyreborg, J. (2011). Safety matters have become too important for management to leave it up to the workers' - The Nordic OSH model between implicit and explicit frameworks. Nordic Journal of Working Life Studies, 1, 135-160.

Eldstad, J. I. (2008). Utdanning og helseulikheter Problemstillinger og forskningsfunn (Rap. no. IS-1573). Helsedirektoratet.Emmons, K. M. \& Biener, L. (1993). The impact of organizational characteristics on hospital smoking policies. American Journal of Health Promotion, 8, 43-49.

Emmons, K. M., Thompson, B., McLerran, D., Sorensen, G., Linnan, L., Basen-Enquist, K., \& Biener, L. (2000). The relationship between organizational characteristics and the adoption of workplace smoking policies. Health Education \& Behavior, 27, 483-501. 
Emmons, K. M., Weiner, B., Fernandez, M. E., \& Shin-Ping Tu (2012). Systems antecedents for dissemination and implementation: A review and analysis of measures. Health Education and Behavior, 39(1), 87-105.

Emont, S. L. \& Cummings, K. M. (1989). Adoption of smoking policies by automobile dealerships. Public Health Reports, 104, 509-514.

Engelstad, F. (red) (2003). Makt og demokrati i arbeidslivet. Oslo: Gyldendal norsk forlag

Esser, I. \& Olsen, K. M. (2011). Perceived job quality: Autonomy and job security within a multi-level framework. European Sociological Review. First published online: February 15,2011

Faghri, P. D., Kotejoshyrer, R., Cherniack, M., Reeves, D. \& Punnet, L. (2010). Assement of a Worksite Health Promotion Readiness Checklist. Journal of Occupational and Environmental Medicine, 52, 893-899.

Friedland, R. \& Alford, R. R. (1991). Bringing society back in: Symbols, practices, and institutional contradictions. In: Powell, W. W. \& DiMaggio, P. J. (Eds.), The New Institutionalism in Organizational Analysis (pp. 232-263). Chicago: University of Chicago Press.

Gestel, N. \& Hillebrand, B. (2011). Explaining stability and change: The rise and fall of logics in pluralistic fields. Organization Studies, 32(2), 231-252.

Gulbransen, T. (2009). I sentrum av kryssende forventninger. ISF Report (2009: 014). Oslo: Institutt for Samfunnsforskning.

Helfrich, C. D., Weiner, B. J., McKinney, M. M., \& Minasian, L. (2007). Determinants of implementation effectiveness: Adapting a framework for complex innovations. Medical Care Research and Review, 64, 279-303.

Heward, S., Hutchins, C., \& Keleher, K. (2007). Organizational change - key to capacity building and effective health promotion. Health Promotion International, 22(2), 170-178

Joerges, B. \& Czarniawska, B. (1998). The question of technology, or how organizations inscribe the world. Organization Studies, 19(3), 363-385.

Kalleberg, A. L., Nesheim, T., \& Olsen, K. M. (2009). Is participation good or bad for workers? Effects of autonomy, consultation and teamwork on stress among workers in Norway. Acta Sociologica, 52, 99-116.

Kalleberg, A. L., Nesheim, T., \& Olsen, K. M. (2010). Perceived job quality in the United States, Great Britain, Norway and West Germany, 1989-2005. European Journal of Industrial Relations, 16, 221.

Kraatz, M. S. \& Block, E. S. (2008). Organizational implications of institutional pluralism. In: Greenwood, R., Oliver, C., Sahlin-Andersson, K., \& Suddaby, R. (Eds.), The Sage Handbook of Organizational Institutionalism. London: Sage Publications Ltd. pp. 243-275.

Kruse, M. M. (2009). From the basic to comprehensive programming. In: Nicolaas, P.P. (Ed.), ACSM'S Worksite Health Handbook. Champain: Human Kinetics. pp. 296-307.

Kunda, G. (1992). Engineering Culture. Philadelphia, PA: Temple University Press.

Linnan, L., Weiner, B., Graham, A., \& Emmons, K. (2007). Manager beliefs regarding worksite health promotion: Findings From the Working Healthy Project 2. American Journal of Health Promotion, 21, 521-528.

Lounsbury, M. (2008) Institutional rationality and practice variation: New directions in the institutional analysis of practice. Accounting, Organizations and Society, 33(4-5), 349-361.

Miles, M. B. \& Huberman, A. M. (1994). Qualitative Data Analysis: An Expanded Sourcebook (2nd ed.). Thousand Oaks, CA: Sage.

Mintzberg, H. (1979). The Structuring of Organizations: A Synthesis of the Research. Englewood Cliffs, NJ: Prentice-Hall.

Ommundsen, Y. \& Aadland, A. A. (2009). Fysisk inaktive voksne i Norge: hvem er inaktive og hva motiverer til økt fysisk aktivitet. [Oslo]: Helsedirektoratet. 
Perrow, C. (1986). Complex Organizations: A Critical Essay (3rd ed.). New York: Random House.

Plotnikoff, R. C., Poon, P. L. P., \& Prodaniuk, T. R. (2011). Can workplace active living work? Perspectives from the Workplace. AVANTE, 10(2), 57-70.

Pronk, N. (2010). Six trends affecting the business case for worksite health promotion. ACSM's Health \& Fitness Journal, 14, 42-43.

Pruijt, H. (2003). Teams between neo-Taylorism and anti-Taylorism. Economic and Industrial Democracy, 24, 77-101.

Renaud, L., Kishchuk, N., Juneau, M., Nigam, A., Tètreault, K., \& Lemonds, D. W. (2008). Implementation and outcomes of a comprehensive worksite health promotion program. Canadian Journal Of Public Health, 99(1), 71-77.

Rørvik, K. A. (2007). Trender og Translasjoner Ideer som former det 21. århundrets organisasjoner. Oslo: Universitetsforlaget.

Rütten, A., Röger, U., Abu-Omar, K., \& Frahsa, A. (2009). Assessment of organizational readiness for health promotion policy implementation: Test of a theoretical model. Health Promotion International, 24(3).

Shalin, K. \& Wedlin, L. (2008). "Circulating Ideas: Imitation, Translation and Editing.” in iIn: Royston Greenwood, R., Christine Oliver, C., Kerstin Sahlin-Andersson, K., \& Roy Suddaby, R. (Eds.), The Sage Handbook of Organizational Institutionalism., edited by Royston Greenwood, Christine Oliver, Kerstin Sahlin-Andersson, and Roy Suddaby: London: Sage Publications Ltd. pp. 218-242.

Scott, W. R. (2008). Lords of the dance: Professionals as institutional agents. Organization Studies, 29, 219-238.

Selznick, P. (1984). Leadership in Administration: A Sociological Interpretation. California: Harper \& Row Publishers.

Shain, M. \& Kramer, D. M. (2004). Health promotion in the workplace: Framing the concept; reviving the evidence. Occupational and Environmental Medicine, 61, 643-648.

Skorstad, E. J. (1999). Produksjonsregimer i det tyvende århundre. Ad Notam Gyldendal.

Sloan, R. P. and Grumen, J. C. (1988). Participation in workplace health promotion programs: The contribution of health and organizational factors. Health Education Quarterly, 15, 269-288.

Sparling, P. B. (2010). Worksite health promotion: Principles, resources, and challenges. Preventing Chronic Disease, 7, 1-6.

Spicer, A. (2006). Beyond the convergence-divergence debate: The role of spatial scales in transforming organizational logic. Organization Studies, 27, 1467.

Thornton, P. H. (2002). The rise of the corporation in a craft industry: Conflict and conformity in institutional logics. Academy of Management Journal, 45, 81-101.

Thornton, P. H. \& Ocasio, W. (2008). Institutional logics. In: Greenwood, R., Oliver, C., Sahlin K., \& Suddaby, R. (Eds.), The SAGE Handbook of Organizational Institutionalism. London: Sage, pp. 99-129.

Watson, T. J. (2009). Sociology, Work and Industry. London: Routledge.

Weick, K. E. (1995). Sensemaking in Organizations. Thousand Oaks, CA: Sage.

Weiner, B. J. (2009). A theory of organizational readiness for change. Implementation Science, 4, 67.

Witte, K. (1993). Managerial style and health promotion programs. Social Science o Medicine, 36(3), 227-235 